\title{
A CONSTRUÇÃO DO ETHOS EM SHREK 2 (2004): O HUMOR EM CENAS ENUNCIATIVAS
}

Luiz Antonio Xavier Dias (Doutorando pelo Programa de Pós-graduação em Estudos da Linguagem - - UEL) ${ }^{1}$

Prof. Dra. (Edina Regina Pugas Panich - Orientadora do Programa de Pós-graduação em Estudos da Linguagem - UEL) ${ }^{2}$

Este trabalho tem como objetivo analisar a construção do ethos em duas cenas enunciativas de um filme da esfera literária: Shrek 2 (2004). Interessa-nos como se dá a construção dos enunciados concretos verbais e não verbais para a construção de seu ethos, para tanto, será observado seu processo criativo que resultou na formação discursiva, além de um olhar voltado para a linguagem cinematográfica, seus planos de câmera, seus movimentos e também seu aporte sonoro. A pesquisa em foco parte dos pressupostos teóricos da Análise do Discurso de orientação Francesa, além da construção teórica de Ethos gestada pela AD em Maingueneau (2008) e Charaudeau; Maingueneau (2004), e também ao constructo teórico de Oliveira; Machado (2013), em Bakhtin/Voloshinov (1992), na teoria sobre humor de Propp (1992). Justifica-se a teorização do humor uma vez que Shrek 2 (2004) vale-se desse recurso, também, para a construção de sentidos.

Palavras-chave: Ethos; Análise do Discurso, Shrek 2 (2004); Humor.

\section{CONSIDERAÇÕES INICIAIS}

A partir da base teórica pautada nos fundamentos da Análise do Discurso doravante AD, de Linha Francesa, Maingueneau (2008), Charaudeau e Maingueneau (2004), em aplicações teóricas propostas por Orlandi (2005), nos estudos teóricos de Oliveira e Machado (2013), na construção do humor exposta por Propp (1992) e também na noção de ethos gestada pela $\mathrm{AD}$, neste artigo, apresentamos o resultado de pesquisa teórica que procurou investigar a noção de ethos em duas cenas enunciativas da obra cinematográfica Shrek 2 (2004).

Justifica-se também a opção de se trabalhar com enunciados concretos do filme em apreço uma vez que para Vanoye e Goliot-Lété (1994, p. 55) um filme pode ser utilizado para se analisar uma sociedade, visto que ele oferece um conjunto de representações, as quais remetem à sociedade real, de modo direto ou indireto. Para uma interpretação sócio-histórica, a hipótese diretriz é a de que um filme sempre faz alusão ao presente, ao seu contexto de produção. No filme, "a sociedade não é propriamente mostrada, é encenada” (VANOYE; GOLIOT-LÉTÉ, 1994, p. 56)

Além disso, o cinema é a mais semiótica de todas as artes, para isso retomamos as palavras do mestre russo "Tudo o que é ideológico possui um valor semiótico (BAKHTIN/VOLOSHNOV, 1992, p.32). Semiótico é o que o cinema é em sua primeira impressão, na sua primeira forma de análise. Di Camargo Jr. (2009, p. 23) ressalta que ao analisar um filme, primeiro nos damos conta do caráter semiótico, mas

\footnotetext{
${ }^{1}$ E-mail: laxdias@uenp.edu.br

2 E-mail: edinapanichi@sercomtel.com.br
} 


\section{SEMINÁRIO DE PESQUISA EM CIÊNCIAS HUMANAS - SEPECH \\ Humanidades, Estado e desafios didático-científicos \\ Londrina, 27 a 29 de julho de 2016}

Somente após essa primeira absorção dessa realidade que vai ali se desenrolado e se desenvolvendo é que passamos a prestar atenção em detalhes e características mais dialógicas ou intertextuais que estas obras carregam implicitamente em si, como se fossem um código a ser decifrado por caçadores de enigmas, prontos a desvendar ali o seu gênero.

O presente trabalho é, também, fruto de reflexões advindas da disciplina de Análise do Discurso ministrada no Programa de Pós - Graduação, strictu sensu em Estudos da Linguagem da Universidade Estadual de Londrina, e, na presente pesquisa buscamos investigar a construção do ethos em algumas cenas enunciativas da obra Shrek 2 (2004).

\section{ETHOS: DA ANTIGUIDADE CLÁSSICA À VISÃO GESTADA PELA AD}

Inicialmente, a percepção sobre o ethos foi advinda da Antiguidade Clássica, para demonstrar persuasão pelos oradores ao interagiram com um auditório. Assim, o autor clássico mais lembrado que retratou a visão de ethos foi Aristóteles. No início, essa teoria era extremamente ligada à Retórica, ou seja, uma categoria essencialmente discursiva que se relacionava com a instância enunciativa, envolvendo, portanto, sujeitos discursivos e não sujeitos empíricos.

Nesse sentido, o ethos ligava-se, portanto, à instância do discurso, sendo concebido como a imagem criada pelo enunciador no momento em que o mesmo tomava a palavra e enunciava. Para Oliveira e Machado (2013) o ethos é, na realidade, a imagem do enunciador criada no momento da enunciação, pois, "A enunciação é a acentuação da relação discursiva com o parceiro, seja este real ou imaginado, individual ou coletivo." (BENVENISTE, 1989, p.84 apud MACHADO e OLIVEIRA, 2013, p. 6).

Antes de fazermos as definições mais profundas sobre ethos, foco do trabalho, faremos uma breve conceituação sobre texto e discurso, enunciado e enunciação ${ }^{3}$. Ao considerarmos a noção de textos verbais e não verbais como o filme de animação devemos resgatar uma noção mais abrangente, para tanto, observamos a visão de Orlandi (2005):

Consideramos o texto como uma unidade. Como já referimos, esta é uma unidade feita de sons, letras, sinais diacríticos, margens, notas, imagens, sequencias, com uma extensão dada, com (imaginariamente) um começo, meio e fim, tendo um autor que se apresenta em sua origem, com sua unidade, lhe propiciando coerência, não-contradição, conferindo-lhe progressão e finalidade. $\mathrm{O}$ texto se apresenta como um todo em sua unidade (imaginária). O trabalho simbólico do sujeito colocar em palavras "o que tem na cabeça" converte o discurso em texto (ORLANDI, 2005, p.112).

\footnotetext{
${ }^{3}$ Brandão (2004, p. 36) retoma Foucault para definir enunciado e enunciação. Enunciado se dá toda vez que alguém emite um conjunto de signos; enquanto a enunciação se marca pela singularidade, pois jamais se repete, o enunciado pode ser repetido.
} 


\section{SEMINÁRIO DE PESQUISA EM CIÊNCIAS HUMANAS - SEPECH \\ Humanidades, Estado e desafios didático-científicos \\ Londrina, 27 a 29 de julho de 2016}

Brandão (2004, p. 11) define a linguagem enquanto discurso como interação, "é um modo de produção social; ela não é neutra, inocente e nem natural, por isso o lugar privilegiado de manifestação da ideologia. Ela é o "sistema-suporte das representações ideológicas".

Charaudeau e Maingueneau (2004) apud. Oliveira e Machado (2013), assinalam que há o chamado ethos prévio ou pré-discursivo. Apesar de alguns conflitos que tal noção possa trazer, faz referência mais ao aspecto extradiscursivo do que à enunciação propriamente dita, o ethos pré-discursivo diz respeito à representação que se tem do locutor, antes mesmo que ele se manifeste (está relacionado à imagem prévia que os alocutários fazem de seu locutor), (OLIVEIRA; MACHADO 2013, p. 6- 7).

Enquanto o ethos pré-discursivo está relacionado ao gênero de texto, o ethos discursivo está ligado ao discurso (ethos dito) e aos aspectos paralinguísticos (ethos mostrado), como entonação, gestos, expressões do rosto e do corpo, entre outros. Além desses há o ethos coletivo, que está ligado à noção de estereótipos dos sujeitos.

Maingueneau (2008, p. 17) assinala que "a noção de ethos, que mantém um laço crucial com a reflexividade enunciativa, permite articular corpo e discurso paraalém de uma oposição empírica entre oral e escrito", ligado à cena de enunciação ${ }^{4}$. A seguir, construímos um pequeno organograma para melhor sintetizar a noção de Ethos gestada pela AD.

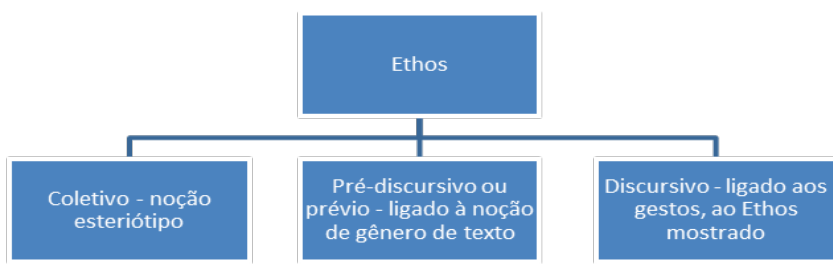

Organograma 1 - Síntese sobre a noção de Ethos por Maingueneau (2008).

\section{ETHOS EM SHREK 2 (2004): A CONSTRUÇÃO DO HUMOR EM CENA}

Em relação às condições de produção da obra cinematográfica Shrek 2 (2004), considera-se o filme como unidade significativa, com junção do verbal e não-verbal, que materializa o discurso. Esse discurso angariou mais de 4.427 .115 espectadores, de acordo com a revista Cinema (jun/2007, p. 19).

Em sua constituição deve-se a uma tecnologia avançada e três anos de dedicação por parte da equipe de produção. Segundo documentário presente nos recursos especiais (notas técnicas), o filme Shrek2 foi produzido exclusivamente com a utilização de programas de informática. Desse modo, havendo uma preocupação com os movimentos faciais e os movimentos dos tecidos (roupas, cortinas), além de folhas, gramas etc. Aplicaram-se técnicas para os efeitos especiais como fluidos e chamas, além disso, a técnica de desenho computadorizado ainda não havia sido aplicada em personagens humanos.

${ }^{4}$ De acordo com Maingueneau (2008) considerar uma cena de enunciação em detrimento de uma situação de comunicação nos permite, de certo modo, considerar o processo de comunicação a partir de seu "interior", mediante a situação que a fala pretende definir. Por isso, essa noção de cena da enunciação é desmembrada em três cenas complementares, a saber, a cena englobante a saber, a cena englobante, a cena genérica e a cenografia. 


\section{SEMINÁRIO DE PESQUISA EM CIÊNCIAS HUMANAS - SEPECH \\ Humanidades, Estado e desafios didático-científicos \\ Londrina, 27 a 29 de julho de 2016}

Seu enredo consiste na construção de um conto de fadas contemporâneo. Após se casar com a Princesa Fiona (Cameron Diaz), Shrek (Mike Myers) vive feliz em seu pântano. Ao retornar de sua lua-de-mel Fiona recebe uma carta de seus pais, que não sabem que ela agora é um ogro, convidando-a para um jantar juntamente com seu grande amor, na intenção de conhecê-lo. A muito custo Fiona consegue convencer Shrek a ir visitá-los, tendo ainda a companhia do Burro interpretado por (Eddie Murphy). Porém, os problemas começam quando os pais de Fiona descobrem que ela não se casou com o Príncipe (Rupert Everett), a quem havia sido prometida, e enviam o Gato de Botas (Antonio Banderas) para separá-los.

A obra em apreço traz diversos efeitos de humor, o mais recorrente é a paródia, que pode ganhar o sentido de uma imitação, uma subversão ao que já foi dito. Pela ótica de Sant'anna (1995) a paródia deforma o texto original, subvertendo sua estrutura de sentido original.

Na obra cinematográfica Shrek 2 (2004) há muitas paródias, dentre elas há passagem com o personagem Pinóquio, que ao tentar salvar Shrek quando está preso em um calabouço está usando roupa íntima feminina. Assim como essa, Shrek 2 (2004) traz muitas passagens humorísticas.

Propp (1992) assinala que as condições para suscitar a comicidade são, primeiramente, quem ri tem que ter pelo menos uma noção das exigências morais da natureza humana, algumas concepções do que seja justo e correto, e, por último, quando rimos é porque encontramos no mundo algo que contradiz o que consideramos certo dentro de nós, ou seja, algum defeito no mundo. "A contradição entre esses dois princípios é a condição fundamental, o alicerce para o nascimento da comicidade e do riso que dela se produz" (PROPP, 1992, p. 174).

Nesse sentido, PROPP (1992) ressalta que o riso acontece quando as descobertas são inesperadas, a piada só é engraçada devido ao seu final inesperado e espirituoso, mas quando a ouvimos mais de uma vez, ela não é mais engraçada porque não há surpresa.

A seguir, serão projetados pequenos fotogramas representativos do filme e também a decupagem de parte dele e posteriormente passaremos a análise dos três tipos de ethos, foco do trabalho.
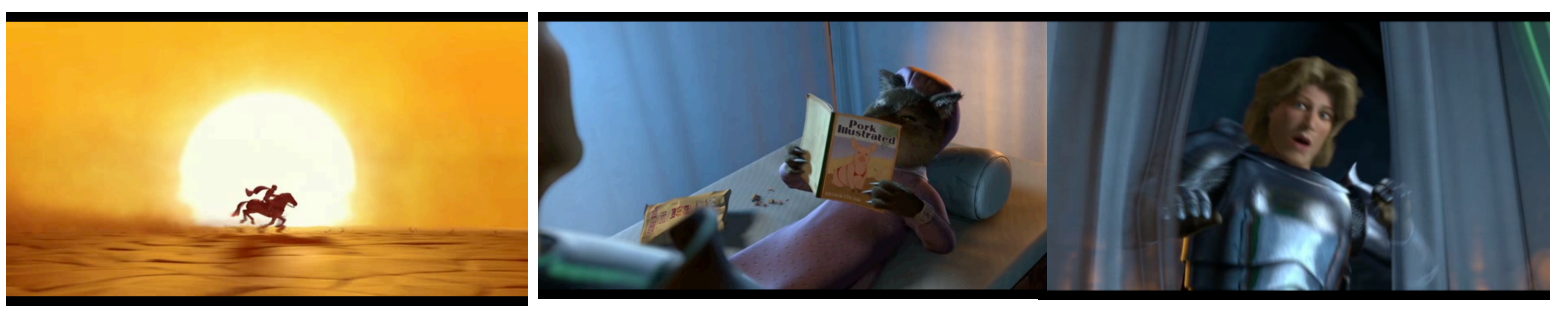

Fotogramas 1 ao 3 - Shrek 2 (2004) - chegada de Encantado à masmorra de Fiona.

Sob o fundo musical romântico orquestrado, travelling vertical em plongée na tela preta acompanha um foco de luz que estaciona em um livro de aparência antiga. O livro se abre e suas folhas viram-se gradativamente, mostrando uma historia ilustrada enquanto uma voz off masculina lê o conteúdo do livro. 


\section{SEMINÁRIO DE PESQUISA EM CIÊNCIAS HUMANAS - SEPECH \\ Humanidades, Estado e desafios didático-científicos \\ Londrina, 27 a 29 de julho de 2016}

Voz masculina (off): "Era uma vez em um reino tão, tão distante um rei e uma rainha que foram abençoados com uma linda menininha e por toda a parte o povo era feliz, até o sol se pôr e eles virem que sua

filha estava amaldiçoada por um terrível feitiço que acontecia todas as noites, desesperados procuraram a fada madrinha que os fizeram trancafiar a jovem princesa em uma torre em que ela esperaria pelo beijo de uma príncipe encantado.

Som de cavalo trotando, câmera em travelling lateral, seria ele que enfrentaria a jornada através do frio cortante, do deserto escaldante para enfrentar um terrível dragão, pois ele era o mais corajoso e o mais belo .... enfrentaria um dragão e subiria na torre mais alta, do castelo mais alto câmera em plongée... close no rosto do príncipe encantado... desloca-se até o quarto da princesa, abre as cortinas e toma um susto... em close, no lugar da princesa está o lobo mau lendo uma história...

Príncipe encantado diz: Princesa Fiona?

Lobo mau: - nããão!!!

Encantando: Graças a Deus!!!!

Lobo mau: Ela está em lua de mel.

Encantado: - Mas onde?

(SHREK 2, PDI/DreamWorks, 2004)

No presente trecho, a partir das transcrições, percebemos que há a mistura do tempo verbal pretérito imperfeito do modo indicativo, era... e também a utilização do futuro do pretérito (seria), atravessaria, para designar o personagem Encantado como uma possibilidade de ser salvador da princesa. No caso, o futuro do pretérito, também chamado de condicional é usado para falar de um acontecimento futuro em relação a outro já ocorrido, fato que poderá ou não ocorrer, algo incerto fazendo hipóteses ou suposições, surpresa ou indignação sobre um evento ou dar sugestões e fazer pedidos de maneira mais educada, ou seja, é apresentada uma possibilidade de Encantado encontrar sua princesa. Há, no entanto, uma quebra de expectativa do ethos discursivo, nele, o expectador vai construindo uma imagem de que haverá um final feliz, marcado à noção do gênero discursivo, no caso, os contos de fadas terminam sempre com o príncipe encantando ficando com a mulher amada.

Todavia, o que constrói um novo efeito de sentido é justamente essa quebra de expectativa do expectador, a qual Encantado tentaria beijar a princesa e acaba se deparando com um lobo mal usando a roupa da vovó e lendo um livro de sua própria história. Para Propp (1992, p. 46), “a comicidade encontra-se na correlação entre natureza física e espiritual, sendo que a primeira põe à mostra os defeitos do segundo, logo o corpo humano pode se tornar ridículo, constituindo o objeto risível".

$\mathrm{Na}$ cena enunciativa analisada anteriormente, consideramos também a paródia por subversão, a qual atribui um novo sentido aos contos de fadas que já estavam cristalizados, ou seja, o ethos discursivo constrói uma significação a qual o ideal era que um príncipe encontrasse sua amada princesa, uma bela moça deitada em um leito, além disso, há a referência explícita a dois contos de fadas tradicionais $A$ bela adormecida e aos Três porquinhos, mas que, devido à inovação da obra atribui-se um sentido inesperado no fio do discurso e acaba gerando o humor da cena.

Outro ponto relevante na construção do ethos pré-discursivo é a relação das câmeras com a cena. No caso em apreço, elas se movimentam em travelling lateral, 


\section{SEMINÁRIO DE PESQUISA EM CIÊNCIAS HUMANAS - SEPECH \\ Humanidades, Estado e desafios didático-científicos \\ Londrina, 27 a 29 de julho de 2016}

indicando o sofrimento de Encantado, outro momento importante é que ao retirar uma parte da armadura de cavaleiro, ele deixa seus cabelos esvoaçarem, novamente a construção de um ethos de alguém que é esnobe, tal hipótese ideológica é confirmada

no decorrer do filme. Há também a mudança dos cenários, chuva, frio, desertos terríveis para que Encantado encontrasse sua princesa.
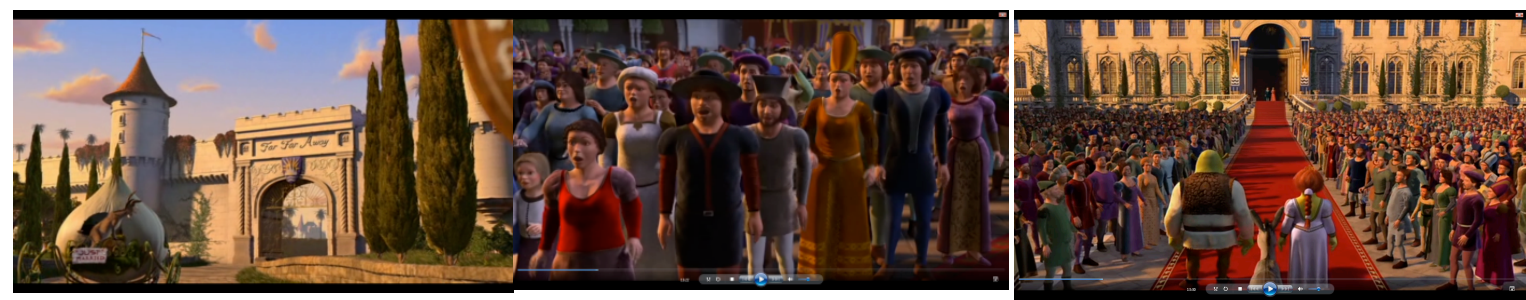

Fotogramas 4 ao 6 de Shrek 2 (2004) - A chegada do casal protagonista ao Reino

A segunda cena enunciativa descrita do filme para este trabalho é o momento em que Shrek e Fiona são convidados a se deslocarem ao palácio dos pais de Fiona para que o casal consiga uma bênção real, os dois se deslocam em uma carruagem durante alguns dias e o burro fiel também se desloca com o casal. No decorrer da viagem os três vão observando a paisagem e ao entrarem na cidade do Reino Tão, Tão Distante iniciase a trilha sonora da música Fukytown da banda Lyps.

Tal trilha é animada e a tradução de sua letra sugere movência, no refrão há as expressões traduzidas: Preciso me mover para uma cidade; que é certa para mim; cidade que me mantenha movendo; me mantenha dançando com alguma energia. Após o final da trilha os três chegam à entrada do palácio e um servo anuncia: - Anuncio a tão esperada volta da linda princesa Fiona com seu novo marido. Close na abertura da trave da carruagem, libertam-se pombas brancas e ao fundo aparece o casal de ogros, no quadro seguinte a população se assusta e fala ahhhh. Aqui constatamos o choque identitário com a palavra Bela, no caso, o ethos coletivo que se tem de belo é convencionado previamente, dessa maneira, os cidadãos ficam chocados pois o belo para eles não é o mesmo que um belo Ogro ou Ogra.

O que se pode constatar na presente cena enunciativa é a presença do ethos coletivo de decepção de toda a população e também dos pais, pois toda a cidade tinha um esteriótipo de príncipe e princesa, mas o que acontece, na verdade é a aparição de dois ogros e um burro atrás das cortinas. Tais fatos podem ser comprovados pelos fotogramas 5 e 6, marcado pela expressão de decepção dos cidadãos de Tão Tão Distante...

\section{CONSIDERAÇÕES FINAIS}

A análise da representação do ethos nas duas cenas da obra cinematográfica Shrek 2 (2004) pode dar uma pequena mostra de como o ethos é construído a partir de marcas linguístico-enunciativas e de pistas não verbais, além de uma construção sócio historicamente marcada. A partir desse pequeno corpus, constatamos que o gênero parodístico e também a quebra de expectativa é muito relevante na construção do ethos seja discursivo ou coletivo. Cabe lembrar, que as marcas não-verbais também remetem 


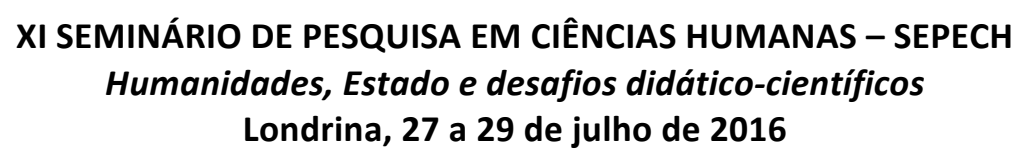

à construção de sentidos e a uma representação ideológica. Mais que fantasia, essa obra, além de resgatar sensações e emoções é um ótimo material linguístico discursivo para se

trabalhar valores de uma sociedade estereotipada pela desconstrução desses valores já cristalizados e marcados.

\section{REFERÊNCIAS}

BAKHTIN, Mikhail Mikhailovitch (Volochinov). Marxismo e filosofia da linguagem. 9. ed. São Paulo: Hucitec, 1992.

BENVENISTE, Émile. Problemas de Linguística Geral II. São Paulo: Pontes, 1989.

BRANDÃO, Helena Hathsue Nagamine. Introdução à Análise do Discurso. 2. Ed. Campinas - SP: Editora da Unicamp, 2004.

CHARAUDEAU, Patrick; MAINGUENEAU, Dominique. Dicionário de Análise do Discurso. Tradução Fabiana Komesu. São Paulo: Contexto, 2004.

DI CAMARGO, Ivo Jr.. O futuro analisado pela linguagem cinematográfica: diálogos entre a teoria do cinema e Mikhail Bakhtin.”. Dissertação de Mestrado. Programa de Pós-Graduação em Linguística da Universidade Federal de São Carlos - UFSCar, São Carlos, 2009.

MAINGUENEAU, Dominique. Cenas da enunciação. Tradução de Sírio Possenti, Maria Cecília Pérez de Souza-e-Silva, Nélson de Barros da Costa et all. São Paulo: Criar Edições, 2008.

OLIVEIRA, Esther Gomes de; MACHADO, Rosemeri Passos Baltazar. O ethos em (cena): a força argumentativa do humor. Verbum, v. 3, p. 4-24, 2013.

ORLANDI, Eni Pucinelli. Discurso e texto: formulação e circulação de sentidos. 2. ed. Campinas, SP: 2005.

PROPP, Vladimir I. Comicidade e Riso. São Paulo: Ática, 1992.

SABADIN, Carlos. Shrek mantém encanto do primeiro filme. Revista cinema. São Paulo: Ed. Única. Ano VIII, edição 77, jun./2007.

SANT’ANNA, Affonso Romano de. Paródia, paráfrase \& cia. 2. ed. São Paulo: Ática, 1995.

SHREK 2. Direção : Andrew Adamson. Produção : Jeffrey Katzenberg; Aron Warner. Califórnia: DreamsWorks Animation, 2004, 1 DVD (105 min.) son., color.

VANOYE, F.; GOLIOT-LETE, A. Ensaio sobre a análise fílmica. Trad. Marina Appenzeller. Campinas, SP: Papirus, 1994. 


\section{SEMINÁRIO DE PESQUISA EM CIÊNCIAS HUMANAS - SEPECH}

Humanidades, Estado e desafios didático-científicos

Londrina, 27 a 29 de julho de 2016

XAVIER, Ismail. O discurso cinematográfico: a opacidade e a transparência. São Paulo: Paz e Terra, 2005. 